\title{
Buscando uma definição para o conceito de "conceito"
}

Benildes Coura Moreira dos Santos Maculan

Doutora em Ciência da Informação e Professora da Escola de Ciência da Informação da UFMG, do Departamento de Organização e Tratamento da Informação

Gercina Angela Borém de Oliveira Lima

Pós Doc. em Metodologia para Análise de Assunto pela Universidad Carlos III, Madri - Espanha e Pela ECA/USP. Professora da Escola de Ciência da Informação da UFMG

http://dx.doi.org/10.1590/1981-5344/2963

Apresenta discussões que envolvem o entendimento do conceito nas áreas da Linguística, Terminologia, Biblioteconomia e Ciência da Informação. As análises e reflexões oferecem insumos para o campo de construção de tesauros conceituais, uma vez que nesses instrumentos os conceitos são elementos nucleares $e$ estão inter-relacionados em sua estrutura, estabelecendo relações semânticas entre si (de equivalência, hierárquicas e associativas). As ponderações sobre a significação do conceito resultaram em uma nova proposta, desenvolvida por Maculan (2015), para o conceito de "conceito", que teve por base uma relação triádica, pautada no Triângulo Semântico de Ogden e Richards e no Triângulo do Conceito de Dahlberg.

Palavras-chave: Conceito; Construção de tesauros; Sistemas de Organização do Conhecimento; Organização do conhecimento.

\section{Seeking a definition for the concept of} "concept"

Presents discussions involving the understanding of the concept in the areas of Linguistics, Terminology, Library and Information Science. The analyses and reflections provide inputs to the field of construction of conceptual 
thesauri, because in these instruments the concepts are core elements and inter-related in their structure, establishing semantics relationships between themselves (equivalence, hierarchical and associative). The ponderings about the meaning of the concept resulted in a new proposal, developed by Maculan (2015), to the concept of "concept", which was based on a triadic relation, based on the Semantics Triangle by Ogden and Richards, and the Triangle of the Concept by Dahlberg.

$\begin{array}{lll}\text { Keywords: } & \text { Concept; Thesauri construction of; } \\ \text { Knowledge } & \text { Organization Systems; Knowledge } \\ \text { organization. } & & \end{array}$

Recebido em 17.10.2016 Aceito em 27.06.2017

\section{Introdução}

A discussão acerca do conceito de "conceito" ora apresentada neste artigo foi parte da fundamentação teórica desenvolvida e utilizada na tese de Maculan (2015), que tratou da aplicação de um modelo de reengenharia de tesauro para a explicitação das relações semânticas entre os conceitos nesse tipo de instrumento. A revisão de literatura realizada sobre o conceito fez emergir interessantes questões, sobretudo sobre as semelhanças e diferenças do entendimento do conceito de "conceito" no campo da Linguística, da Terminologia, da Biblioteconomia e da Ciência da Informação. A análise da literatura e as reflexões desenvolvidas levaram a autora a também apresentar uma proposta para o conceito de "conceito", que atenda aos princípios da Teoria Comunicativa de Terminologia (TCT), criada por Cabré (1995; 1999).

Desde a Revolução Industrial, o controle de informações especializadas se faz cada vez mais essencial, exigindo, nesse processo, a necessidade de organizar, representar, armazenar e recuperar informações. Para auxiliar nesse controle, no âmbito dos estudos da Biblioteconomia e da Ciência da Informação, foram desenvolvidas diferentes iniciativas $e$, entre elas, aquelas que deram origem aos tesauros. Pode-se afirmar que os primeiros tesauros possuíam seu vocabulário formado com base em palavras (CAMPOS; GOMES, 2006). Contudo, as autoras esclarecem que a construção de um tesauro acontece na esfera do domínio e não do discurso, o qual é utilizado apenas como estratégia para a coleta de terminologia na literatura da área (garantia literária).

Nessa perspectiva, desenvolve-se um tesauro conceitual (ou tesauro terminológico) que é composto por uma terminologia (conjunto de descritores preferidos e não-preferidos) que tem o conceito como seu elemento nuclear, uma vez que este denota certo nível de abstração e de consenso dentro de um dado domínio. Considera-se que a estrutura de 
um tesauro é um todo articulado de conceitos, e não um conjunto de conceitos independentes. Sendo assim, os conceitos estão interrelacionados no tesauro, estabelecendo entre si relações semânticas (de equivalência, hierárquicas e associativas).

Em analogia à abordagem analítico-sintética de Ranganathan para a elaboração e uso dos sistemas de classificação, é possível atribuir essa abordagem ao que ocorre no campo dos tesauros, que possui uma estrutura conceitual que reúne diferentes conceitos que representam o conhecimento de um dado domínio. Na fase analítica da abordagem analítico-sintética de Ranganathan, um assunto composto ou complexo, dentro de um determinado domínio, é analisado e decomposto até que seja formado apenas por assuntos simples. São estes assuntos simples que serão posteriormente combinados, na fase sintética, da classificação, para representar os assuntos que determinam o conteúdo informacional de um documento. Como será explicitado ao longo deste artigo, Ranganathan considera que o conteúdo de um assunto é o conceito desse assunto, uma vez que devemos considerar que o conceito é o elemento material para os sistemas de classificação (DAHLBERG, 1979). Assim, em analogia à abordagem de Ranganathan, os tesauros também possuem uma estrutura conceitual, composto por diferentes conceitos (representados pelos termos descritores) de um dado domínio, que foram obtidos conforme o mesmo processo analítico de Ranganathan. Na fase sintética, esses conceitos (termos descritores preferidos) podem ser combinados de distintas formas, no momento da indexação, onde os assuntos que descrevem o conteúdo de um documento são formados, a partir dessa combinação.

Nesse sentido, Svenonius (2000) afirma que a junção dos diferentes termos (ou descritores) é que faz com que na estrutura de um tesauro não exista termos sem ligação com outro, sendo que essa conexão está estreitamente relacionada com o conteúdo do seu conceito, que se definem a partir da inter-relação com outros conceitos na estrutura do tesauro. Desse fato advém a importância das discussões acerca do conceito de "conceito" no âmbito dos estudos sobre a construção de tesauros, que se passa agora a examinar, iniciando com a exposição da origem das reflexões acerca do conceito, para, depois, apresentá-lo dentro da Linguística, da Terminologia e, finalmente, na Biblioteconomia e Ciência da Informação.

\section{0 conceito de "conceito" na berlinda}

O termo "conceito" tem origem no Latim conceptus (do verbo concipere), significando "coisa concebida" ou "formada na mente". Na linguagem natural existe polissemia e ambiguidade, pois o termo é utilizado com diferentes acepções, podendo significar noção, juízo, opinião, ideia ou pensamento (FERRATER-MORA, 2004). No Dicionário de Filosofia, Abbagnano (1998, p. 164) afirma que o conceito é 
[...] todo processo que torne possível a descrição, a classificação e a previsão dos objetos cognoscíveis. Assim entendido, esse termo tem significado generalíssimo e pode incluir qualquer espécie de sinal ou procedimento semântico, seja qual for o objeto a que se refere, abstrato ou concreto, próximo ou distante, universal ou individual, etc.

Dessa forma, como objeto cognoscível, o conceito se manifesta como um fenômeno que é apreendido pelo sujeito e cuja função é determinada por um dado contexto.

As reflexões acerca do conceito têm início na Filosofia clássica, havendo diversas visões para o seu significado. Nessa Filosofia, as questões metafísicas ${ }^{1}$ envolvendo conceitos incluem o que é um universal ${ }^{2}$ e a distinção entre diferentes tipos de universais, sendo Sócrates, Platão e Aristóteles, os pioneiros nesses estudos. Para Sócrates, a existência real dos conceitos (ou ideias) é obtida a partir de conceitos abstratos (piedade, coragem ou justiça) e de conceitos concretos (homem, árvore ou pedra), válidos para toda a humanidade, em qualquer tempo e lugar. Com Platão, considerado de um realismo absoluto, o conceito é analisado mais do ponto de vista de um universal real (essência) (FERRATER-MORA, 2004), existindo em um mundo separado, a priori, que está fora dos objetos e fora da mente. Já com Aristóteles, a partir de uma filosofia de realismo moderado, destacam-se os universais como seres inerentes às coisas, cuja existência é dependente de existirem indivíduos nos quais esses universais se exemplificam (FERRATER-MORA, 2004). Sobre isso, Hjorland (2009) afirma que,

Hoje, não há consenso sobre o que são conceitos, quais teorias do conceito são mais importantes e como as teorias do conceito podem ser classificadas [...] [havendo] diferentes visões sobre conceitos, de grandes filósofos e cientistas, que estão associadas com distintas visões epistemológicas e do mundo e cada uma delas estão inclinadas a competirem entre si (HJORLAND, 2009, p. 1519).

Assim, dependendo da visão epistemológica adotada, o conceito de "conceito" difere, o que justifica um exame mais reflexivo sobre esse tema.

Dentro do pensamento filosófico, Abbagnano (1998) afirma que da noção de conceito emerge o problema sobre a sua natureza, que deu origem a duas soluções possíveis. Para o autor, a primeira advém do período clássico da filosofia grega e considera o conceito como a essência necessária das coisas, como parte constituinte do próprio objeto e, assim,

\footnotetext{
${ }^{1}$ São as questões filosóficas sobre a essência das coisas do mundo, a quais categorias elas pertencem e quais são as relações que possuem entre si.

${ }_{2}^{2}$ Dependendo da acepção adotada, um universal é considerado de diferentes formas, podendo ser uma entidade da realidade ou a uma etiqueta atribuída para representar objetos ou eventos particulares, de forma arbitrária.
} 
é imutável, independente da perspectiva sob a qual o objeto é analisado. Sobre a segunda solução, Abbagnano (1998) declara que vem dos primórdios da filosofia grega, quando o conceito é referido como um signo que representa um objeto e que tem uma relação de significação com ele, que é fixado de forma arbitrária e convencionalmente. Para Borba (1998, p. 19),

O signo também é arbitrário na medida em que cada sistema linguístico adota como pertinentes ou não determinadas características que constituirão as classes de significantes e significados que utiliza. [...] $\mathrm{O}$ signo linguístico transmite (ou veicula) uma informação servindo-se de uma parte material e perceptível associada a uma parte imaterial e inteligível. A parte sensível é o significante e a parte não sensível é o significado.

Nesse sentido, o signo tem como objetivo veicular um discurso linguístico e é composto pelo significante e significado. Isoladamente, o signo é um elemento hermético e somente com o contexto o seu significante recebe um significado e a capacidade de significar em conformidade com o que é exigido dele.

Ainda que haja outras discussões possíveis, neste artigo será apresentada a noção de signo como elemento de comunicação. Para o ser humano, o signo tem uma grande utilidade, a da comunicação, pois é com o signo que ele entende o mundo ao seu redor, a si mesmo e as pessoas de sua relação social (profissional ou pessoal).

\subsection{0 "conceito" na Linguística}

Na Linguística, os estudos sobre a linguagem se iniciam por razões religiosas, com os hindus, sendo o gramático hindu Panini (século IV a.c.) um dos primeiros a descrever sua língua, cuja estrutura de análise foi descoberta no Ocidente, ao final do século XVIII (FIORIN et al., 2003). Contudo, segundo Fiorin et al. (2003), foram os gregos os pioneiros na tentativa de definir a existência ou não de relações entre o conceito (aqui entendido como o significado) e o signo que o designa.

Somente com os estudos de Ferdinand de Saussure (1857-1913), professor da Universidade de Genebra, no início do século XX, e com a publicação da obra com o Curso de Linguística Geral, em 1916, a Linguística passa a ser considerada uma disciplina científica autônoma (FIORIN et al., 2003). Juchem (2008) afirma que Saussure distingue o conceito de "linguagem" do conceito de "língua" (termos que em inglês são traduzidos por um único termo: "language"). Segundo a autora, para Saussure a linguagem é um fenômeno que abrange diversos problemas, que são também analisados por outras disciplinas, tais como a psicologia e a antropologia, "além de pertencer ao social e ao individual - língua e 
fala" (JUCHEM, 2008, p. 13). Para a autora, a língua, parte essencial da linguagem, é considerada por Saussure como o objeto de estudo da Linguística, sendo um produto social (permanente na coletividade) e composta por um conjunto de convenções necessárias para a comunicação. Entretanto, Bornemann (2011) alerta para o fato de que Saussure sugere que é infrutífero estudar a língua, em suas distintas manifestações, sem considerar a linguagem, que é a sua generalização.

Dubois et al. (1997, p. 135) afirmam que no campo da Linguística "dá-se o nome de conceito a toda representação simbólica, de natureza verbal, que tem uma significação geral conveniente a toda uma série de objetos concretos que possuem propriedades comuns". Sobre isso, Maimone e Tálamo (2011, on-line) apontam que "pelo trabalho no plano simbólico, a Linguística cria conceitos que ordenam a realidade e categorizam o mundo". Corroborando com essa afirmativa, Juchem (2008) assinala que Saussure se debruçou sobre o estudo da língua, considerada por ele como passível de definição e classificação, sendo contrário ao pressuposto de que as ideias são anteriores às palavras, pois a língua é um contrato social e, portanto, criado a posteriori.

Nascimento (2008) aponta que para Saussure o conceito é sinônimo de significado, sendo formado no plano das ideias e representa uma realidade social (ou objeto), pois

A língua, até então concebida como uma simples nomenclatura, é entendida, por ele [Saussure], como um sistema de signos [semiológico], e o signo como uma unidade de duas faces: conceito e imagem acústica. Com a concepção da dupla face sígnica, elimina a falácia do objeto que é extralinguístico. A união de um significado e um significante, denominações dele também para conceito e imagem acústica, é resultado de uma convenção, estabelecida pela significação. O signo é então uma unidade arbitrária (NASCIMENTO, 2008, p. 272).

Saussure defende uma ligação inerente entre o significante (imagem acústica: signo), que é utilizado como elemento de comunicação, e o seu significado (conceito: representação mental). Nascimento (2008) assinala, portanto, que o signo é constituído de forma arbitrária, como uma unidade com bipolaridade, composto pelo plano da forma (significante) e pelo plano da substância (significado):

Por exemplo, o conceito de Sol não está ligado nem com o som da sua sequência de letras e nem com a imagem acústica (significante), pois esse mesmo conceito pode ser representado, em outros idiomas, com outros significantes, tais como Sun (inglês), Soleil (francês) ou Sonne (alemão) (MACULAN, 2015, p. 90). 
Dessa forma, nota-se que o signo é determinado pelo grupo social que o compartilha, notadamente de forma arbitrária, pois, necessariamente, o seu significado não tem relação natural com a realidade ou com os sons fonéticos desse signo (NASCIMENTO, 2008). Silveira (2005) aponta que, nesse caso, o significante é imotivado, uma vez que pode ser representado em conformidade com os compromissos estabelecidos dentro de uma comunidade (contextos de uso).

Maimone e Tálamo (2011, on-line) alertam para o fato de que "a arbitrariedade do signo não se aplica a todas as linguagens já que algumas são motivadas, como por exemplo, as linguagens visuais". Contudo, Nascimento (2008) destaca que Saussure reconheceu a existência de certos graus de motivação entre significante e significado, propondo dois tipos de arbitrariedade: (1) a absoluta: relação totalmente arbitrária (imotivada) entre o significante e o significado; por exemplo, para a ideia de criança (significante), pode haver diferentes significados (menina, guria) dependendo do acordo estabelecido pelo grupo social; e (2) a relativa: tem a relação arbitrária, entre o significante e o significado, abrandada (motivada); por exemplo: para a ideia de 19 (significante) há o significado "dezenove", que é a junção de dez e nove, já anteriormente acordados, dando origem, por essa razão, a uma relação arbitrária motivada.

Uma das mais recorrentes críticas ao pensamento saussuriano, segundo Carvalho (2003), é relativa à análise do signo como elemento bifacial, composto pelo significado (conceito) e significante (imagem acústica). Na obra "Kaspar Hauser ou a Fabricação da Realidade", Blikstein (1983) faz críticas a esse posicionamento de Saussure e afirma que na avaliação do signo deve-se também levar em consideração o referente. Para Blikstein (1983), o referente permite apreender características da realidade que está fora do sistema linguístico (extralinguístico), pois estabelece uma ligação com o contexto no qual a comunicação ocorre. Nesse sentido, Carvalho (2003) analisou o triângulo do significado de Ogden e Richards, que tem como ponto central as relações ocorridas entre os elementos da tríade: significado (conceito), significante (expressão) e referente (objeto), e apresentou uma combinação desse triângulo à teoria de Saussure, conforme as Figuras 1 e 2 a seguir.

Figura 1 - Triângulo de Ogden e Richards

Figura 2 - Relação triádica formulada para a teoria de Saussure 


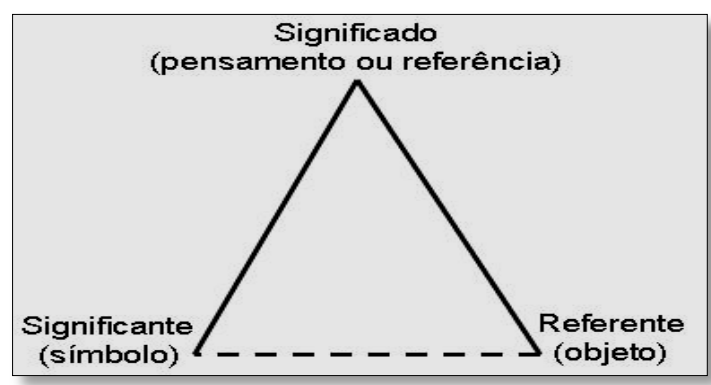

Fonte: CARVALHO (2003, p. 50).

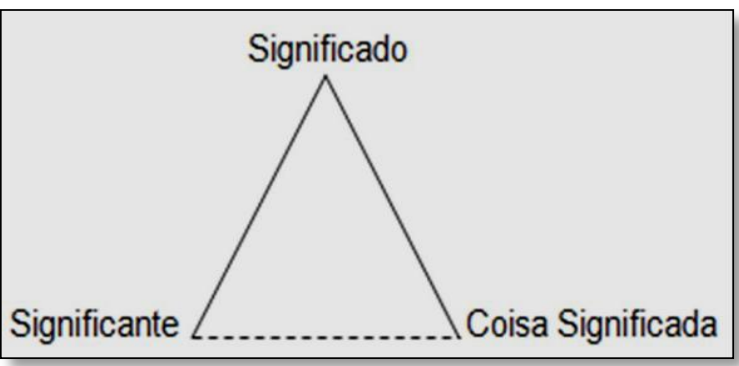

Fonte: CARVALHO (2003, p. 50).

Assim, Carvalho (2003) reformulou a teoria de Saussure criando uma tríade para ela e juntou, aos elementos "significante" e "significado", o terceiro elemento, a "coisa significada", que é o referente do triângulo de Ogden e Richards. Na sugestão de Carvalho (2003), a linha pontilhada da base do triângulo de Ogden e Richards é preservada, indicando não haver um vínculo direto e indissociável entre o referente e o símbolo (significante), postura que não é sustentada na teoria de Saussure.

Blikstein (1983) apresenta outros estudiosos que estabeleceram uma relação triádica para a composição do signo, tais como: (1) Pierce: usa a denominação "representamen" ou "signo" no lugar de "significante", e usa o nome "interpretante" no lugar de "significado", assim como usa a designação "objeto" no lugar de "referente"; (2) Morris: usa a denominação "veículo sígnico" em vez de "significante", usa a designação "interpretante" em vez de "significado" e usa o nome "designatum" em vez de "referente"; (3) Ullmann: usa as denominações "significante" e "significado" da mesma forma que Ogden e Richards, porém, utiliza a designação coisa em vez de "referente". Acrescenta-se a esses o triângulo de Fugmann (1993) que utiliza a tríade "referente", "conceito" e "expressão" para a formulação de sua Teoria de Indexação. Segundo Blikstein (1983, p. 47), na abordagem triádica o "referente" (ou outra designação utilizada) é considerado a interpretação (percepção; ponto de vista) de uma dada realidade, uma vez que a língua "não recorta a realidade propriamente, mas a realidade fabricada", construída na praxe social.

A questão do conceito, ou da significação, na Linguística, pode ser esclarecida pela afirmação:

[...] a estrutura confere às partes a sua "significação" ou sua função. Isso é também o que permite a comunicação indefinida: como a língua é organizada sistematicamente e funciona segundo as regras de um código, aquele que fala pode, a partir de um pequeníssimo número de elementos de base, constituir signos, depois grupos de signos e finalmente uma variedade indefinida de enunciados, todos identificáveis por aquele que os percebe, pois, 0 mesmo sistema está estabelecido nele (BENVENISTE, 2005, p. 24). 
Dessa forma, na Linguística o conceito (significado) é investigado a partir de sua articulação dentro de determinada língua, que é a parte social da linguagem (BORNEMANN, 2011). Nessa perspectiva, a língua é uma manifestação concreta da linguagem e é considerada como um sistema de signos cujas partes possuem conceitos (significados) em conjunto, ou seja, inter-relacionados.

\section{0 "conceito" na Terminologia} básicas:

O termo "terminologia" pode ser considerado por três formas

a) como uma disciplina; b) como uma prática; c) como um produto gerado pela prática. Como disciplina, se ocupa do estudo de termos especializados; como uma prática, é o conjunto de princípios utilizados na compilação de termos; como um produto, é o conjunto de termos de uma especialidade particular (CABRÉ, 1995, p. 2).

Assim, Cabré expõe que a terminologia faz referência a um conjunto de fundamentos epistemológicos, a uma atividade ou a um produto terminológico. Para denominar a disciplina, usa-se Terminologia, com a inicial maiúscula.

A prática da terminologia é antiga e desde 2600 a.C. existem dicionários temáticos monolíngues, e, entre 460-377 a.C., foi elaborado, pelo médico Heródoto e o gramático Herodianus, o primeiro glossário de termos médicos. Depois, vieram os primeiros dicionários bilíngues e de domínios especializados, que uniram os conceitos aos termos que os designam. Os resultados dos estudos na área têm sido substanciais, dando origem a revisões e novas teorias para se adequarem ao desenvolvimento científico e tecnológico.

Somente no século XVII a existência formal de terminologias de especialidade foi aceita, mas foi no século XVIII que os estudos sobre a prática terminológica se ampliaram, devido à profícua criação de terminologias no âmbito das ciências como Biologia e Química (KRIEGER; FINATTO, 2004). Lineu, por exemplo, forneceu uma importante contribuição com seu sistema universal binominal, que criou regras precisas para a construção de nomes científicos para a flora e a fauna (BARROS, 2004). Com a Revolução Industrial, as inovações tecnológicas (nas ciências, no comércio e na administração) deram origem a novas palavras para designá-las, o que exigiu a organização desses termos em terminologias especializadas. Logo após, entre os séculos XIX e adentrando o século $X X$, a internacionalização das ciências deu início às preocupações acerca da padronização terminológica das áreas de especialidade. Com isso, teve início os estudos para a elaboração de regras visando a univocidade na comunicação científica internacional 
(KRIEGER; FINATTO, 2004), quando se fundaram as Escolas de Terminologia (de Viena, de Praga, da Rússia, do Canadá, entre outras).

No trabalho terminológico, o conceito (ou noção) tem função primordial, uma vez que é a análise conceitual (ou nocional) que determina o conteúdo semântico do termo que o designa (BARROS, 2004). Assim, a unidade lexical pode ser estudada do ponto de vista da sua expressão - o termo - ou do ponto de vista do seu conteúdo - o conceito. Em geral,

Ao proceder com o funcionamento social de uma área especializada do conhecimento, a Terminologia trabalha com o estudo científico dos conceitos e respectivos termos, que constituem um conjunto expressivo e comunicativo, possibilitando a transferência do conhecimento especializado. Neste sentido, os conceitos não existem isoladamente, mas sempre uns em relação aos outros (MAIMONE; TÁLAMO, 2011, on-line).

Tal como no campo da Linguística, também na Terminologia os conceitos são considerados como um sistema inter-relacionado de significados, que não podem ser apreendidos isoladamente. Dessa forma, a Terminologia "estuda as chamadas línguas (ou linguagens) de especialidade e seu vocabulário" (BARROS, 2004, p. 21), sendo uma "área teórica e aplicada, com atividade e diretrizes voltadas a diferentes perspectivas e interesses sociais" (KRIEGER; FINATTO, 2004, p. 24).

As investigações nas Escolas de Terminologia tiveram por base dois aspectos: (1) o enfoque cognitivo do fenômeno terminológico, dando ênfase ao elemento normativo da terminologia; e (2) o funcionamento linguístico do termo, com foco na base descritiva do léxico especializado. Esses primeiros estudos sobre a terminologia desenvolveram metodologias para a análise das unidades terminológicas, considerando os termos como designações de conceitos, determinados por vocabulários padronizados.

Os princípios do primeiro aspecto (cognitivo e normativo) foram os aplicados por Eugen Wüster (1898-1977), fundador da Escola Terminológica de Viena, para desenvolver a Teoria Geral da Terminologia (TGT), que é um marco na história dos estudos sobre a Terminologia. Os fundamentos da TGT estão compilados em duas obras: (1) em sua tese, defendida em 1931, "A normalização internacional da terminologia técnica"; e (2) na obra póstuma, "Introdução à Teoria Geral da Terminologia e à Lexicografia Terminológica", publicada por Helmut Felber, originalmente, em 1979, a partir de manuscritos e notas de aulas ministradas na Universidade de Viena entre os anos 1972 e 1974 (KRIEGER; FINATTO, 2004).

A partir de Wüster, no campo da Terminologia, o conceito é considerado como "uma unidade de pensamento constituída por um conjunto de características atribuídas a um objeto ou a uma classe de 
objetos e que pode se exprimir por um termo ou por um símbolo" (BOUTIN-QUESNEL, 1985, p. 18, citado por BARROS, 2004, p. 106). Nessa perspectiva,

Para a TGT, o termo, enquanto signo linguístico, não se compõe de conteúdo e de expressão indissociavelmente ligados. Para essa corrente teórica, o conceito precede a expressão e essas duas facetas são independentes uma da outra. Devido à tônica normalizadora dessa linha teórica, o conceito deve ser estabelecido de antemão e, só então, devese procurar a expressão linguística que mais adequadamente designe o conteúdo terminológico em questão (BARROS, 2006, p. 22).

Dessa forma, o conceito é convencionado no contexto de uso, articulado pela comunidade que o compartilha, para, depois, se proceder à sua designação por meio de um termo que o represente, numa monossignificação ou monorreferencialidade (um termo só pode representar um conceito), típicas do discurso científico. Com essa abordagem, Wüster queria alcançar a univocidade comunicacional, na qual um conceito só pode ser representado por um termo, o que iria eliminar a ambiguidade. De acordo com Finatto (2001), a

[..] necessidade de categorização de tudo o que circunda e constitui a comunicação técnico-científica tem [...] como fim tornar sua expressão mais "exata". A partir e em função dessa perspectiva, Wüster propôs a expressão, a constituição e o estudo das terminologias baseados principalmente em relações lógicas como as de parte-todo, gênero-espécie. Utilizou-se também de oposições binárias e categorias lógicas aristotélicas, estabelecendo categorias fixas e universalmente válidas para a classificação de objetos, produtos de conhecimento e técnicas (FINATTO, 2001, p. 59-60).

Essa concepção positivista e de caráter prescritivo trouxe algumas críticas de estudiosos sobre o tema, sobretudo no que concerne aos aspectos comunicativos e pragmáticos que são inerentes ao léxico (KRIEGER; FINATTO, 2004), dando origem a outras abordagens. Cabré (1993) informa sobre quatro períodos distintos de estudos sobre a Terminologia, entre 1930 e 1990:

(1) de 1930 a 1960: é a origem da Terminologia como disciplina científica, [...] a partir dos estudos de Wüster e Lotte. (2) de 1960 a 1975: surgem os primeiros bancos de dados terminológicos [...] e a preocupação com a recuperação da informação [...]. (3) de 1975 a 1985: há proliferação de normas e a eclosão de terminologias, [...] [com o] tratamento automático e semiautomático de dados [...]. (4) de 1985 a 
1990: a Terminologia passa a ser interesse de estudos de vários pesquisadores, alastrando-se em países europeus, Canadá e também na América Latina, diversificando-se as questões investigadas e os projetos de terminologias para áreas de especialidade [...] (MACULAN, 2015, p. 71).

A esses períodos, Barros (2004) acrescenta um quinto:

[...] a partir de 1990: expansão das reflexões acerca das bases teóricas e metodológicas da Terminologia, com revisões que levam à elaboração de novas abordagens, com enfoque linguístico dos termos e fundamento descritivo da comunicação especializada, dando origem ao empuxo da monorreferencialidade e de univocidade do termo (MACULAN, 2015, p. 71).

Assim, após 1990, a teoria de Wüster, semelhante à concepção de Saussure, que considera o signo como uma unidade indissociável entre significante e significado, recebeu algumas críticas. Contudo, nesse ponto Cabré (1999) ressalta que em áreas tais como a Medicina e a Aviação, que lidam com eventos fatais, a comunicação normalizada proposta pela TGT é essencial para evitar riscos de morte.

A partir das reflexões críticas às ideias da TGT, houve avanços teóricos na área deram origem a novas teorias. Krieger e Finatto (2004, p. 214) asseguram que:

[...] os limites de alcance da TGT expressam o apagamento dos aspectos comunicativos e pragmáticos, inerentes ao léxico das linguagens especializadas. Caracteriza-se desse modo, um forte reducionismo do funcionamento da linguagem, aspecto que, inclusive, se tornou um dos focos principais das críticas à TGT.

Dessa maneira, com os novos estudos, de natureza linguística, "o conceito passou a ser dimensionado em uma perspectiva do significado, unidade de pensamento maior que congrega também elementos pragmáticos" (BARROS, 2006, p. 22).

No início da na década de 1990, François Gaudin estuda as terminologias para a análise da língua, com foco em seu uso social, econômico e comercial, desenvolvendo a Socioterminologia (FAULSTICH, 2006). Para Gaudin (1993), a noção linguística de comunicação não pode ser entendida como uma metalinguagem, pois a Socioterminologia é

[...] um ramo da Terminologia que se propõe a refinar o conhecimento dos discursos especializados, científicos e técnicos, a auxiliar na planificação linguística e a oferecer recursos sobre as circunstâncias da elaboração desses 
discursos ao explorar as ligações entre a terminologia e a sociedade (FAULSTICH, 2006, p. 29).

Para a Socioterminologia, a criação de uma linguagem somente tem sentido se for para facilitar a comunicação dentro de um grupo social e, para tal, é preciso atender às especificidades desse grupo. A terminologia de uma área não pode deixar de reconhecer tais características, uma vez que os termos "são entidades passíveis de variação e de mudança e que as comunicações entre membros da sociedade são capazes de gerar conceitos interacionais [articulados entre os pares] para um mesmo termo ou de gerar termos diferentes para um mesmo conceito" (FAULSTICH, 2006, p. 30). Segundo Krieger e Finatto (2004), Gaudin foi pioneiro ao estabelecer que a variação terminológica também ocorre nas linguagens especializadas.

No final da década de 1990, houve predominância de estudos de caráter descritivo, levando Cabré (1999) à proposta da Teoria Comunicativa da Terminologia (TCT), segundo a qual

[...] o termo é uma entidade poliédrica, ou seja, uma unidade linguística (no sentido que Ihe deu Ferdinand de Saussure), é uma unidade de comunicação e uma unidade cognitiva. Cabré formula a Teoria das portas, segundo a qual os termos podem ser vistos de diferentes ângulos e analisados segundo os modelos das ciências linguísticas, cognitivas e da comunicação, que se considerarem adequados à pesquisa em pauta (BARROS, 2006, p. 23, grifo da autora).

Percebe-se, assim, uma visão multidimensional e poliédrica (é multifacetado e convive com mais de uma dimensão linguística) da terminologia de especialidade (CABRÉ, 1999). Para Cabré (1999), nessa teoria a relação estabelecida entre o termo e o conceito não é de "um para um", pois implica que o conceito é formado pelos elementos: uma situação comunicativa intencional, um contexto de uso e um determinado tempo. A autora considera o conceito como uma unidade de conhecimento que é constituído a partir desses elementos. Tal como Gaudin (1993), Cabré (1999) acredita que a terminologia de especialidade está sujeita às mesmas variações terminológicas e à polissemia que estão presentes na linguagem natural, sobretudo porque, muitas vezes, essas áreas convivem com diversas vertentes teóricas e metodológicas. Para Cabré (1999), o objeto estudado na Terminologia é a junção de três aspectos: o cognitivo (relacionada aos conceitos e definições), o linguístico (formas do signo que representa o conceito) e o comunicativo (uso dos termos em diferentes contextos) (SAGER, 1990).

Os estudos de Rita Temmerman, em 2000, dão origem à Teoria Sociocognitiva da Terminologia (TST), cuja abordagem não considera que há um conceito na realidade que é designado por um termo existente a 
priori. Na perspectiva da TST, o termo é uma construção social, advindo do contexto de comunicação de uma dada especialidade, que é formado em um processo de conceitualização e categorização sociocultural. Temmerman (2000) afirma que esse é um processo hermenêutico, interpretativo, que leva em conta os modelos cognitivos das comunidades discursivas, cujas estruturas são observadas na realidade dessa comunidade e no contexto da comunicação.

Ressalta-se que o interesse primordial do campo da Terminologia tradicional é a elaboração de produtos terminológicos (dicionários; glossários) em que, em geral, trabalham-se com três tipos de conceitos: (a) conceitos próprios de um domínio; (b) conceitos emprestados; e (c) conceitos que ultrapassam o domínio. Por outro lado, as teorias contemporâneas da Terminologia estabelecem que os conceitos, da mesma maneira que os termos que os designam, "não pertencem a um domínio, mas são usados em um domínio com um valor singularmente específico" (CABRÉ, 1999, p. 124). Dessa forma, o princípio da univocidade (um conceito só pode ser representado por um termo) entre o conceito e seu respectivo termo é contestada, pois considera-se que esse princípio não é adequado a todos os propósitos para a elaboração de terminologias de especialidade, dando origem ao princípio da plurivocidade.

\section{0 "conceito" na Biblioteconomia e Ciência da Informação}

No âmbito da Biblioteconomia e Ciência da Informação, há diversos autores que tratam e refletem sobre o tema dos conceitos, dentre os quais destacam-se, mas não se limitam a estes: Ingetraud Dahlberg, Brian Vickery, Maria Antonieta R. Piedade, Maria Luiza Almeida Campos, Hagar Espanha Gomes, Nair Yumiko Kobashi, Mário Barité e Birger Hjorland. Contudo, ao discorrerem sobre os conceitos na área, dois fundamentos teóricos são recorrentemente discutidos: (1) as Teorias da Classificação, em geral, limitando-se à Teoria da Classificação Facetada, desenvolvida por S. R. Ranganathan (1897-1972); e (2) a Teoria Analítica do Conceito, desenvolvida por Ingetraut Dahlberg.

\subsection{Formação do "conceito" segundo a teoria de Ranganathan}

Na teoria, Teoria da Classificação Facetada, influenciado por estudos de Sayers, Bliss, Dewey, Shera, dentre outros (LA BARRE, 2010), Ranganathan cria princípios, cânones e postulados para a construção de sistemas de classificações bibliográficas facetadas para acervos documentários. Essa teoria foi desenvolvida para dar embasamento teórico ao seu sistema de classificação facetado, o Colon Classification. Os 
fundamentos dessa teoria estão publicados em sua obra Prolegomena to Library Classification (Prolegômenos para a Classificação em Bibliotecas), que teve sua primeira edição em 1937, a segunda edição, em 1957 e, a terceira edição, em 1967.

Dentre os fundamentos de sua teoria, Ranganathan (1997c, p. 127) apresenta o assunto (subject) como "o conteúdo considerado [thoughtcontent] de um documento". Para o autor, um assunto básico (basic subject) possui, "em geral, grande extensão, que pode ser dividido com base em um ou mais conjuntos de características" (idem, p. 127). Nessa perspectiva, Ranganathan considera que um isolado é um "termo tomado como tal. Não é o assunto em si, mas, se juntado a um assunto básico, o resultado é um assunto com pouca extensão" (idem, p. 128). Por exemplo: "ouro" é um isolado, que, se juntado a diferentes assuntos básicos, se transforma em distintos assuntos: Economia Geológica do Ouro e Escultura de Ouro.

Em seus escritos, Ranganathan estabeleceu três níveis para uma análise facetada, visando determinar e representar os assuntos dos documentos, conforme descrito por Dahlberg (1979, p. 357):

- o chamado "plano da ideia" - nível das ideias, conceitos; - o "plano verbal" - nível da expressão verbal dos conceitos (que podem variar segundo a língua utilizada); - o "plano notacional" - nível da fixação dos conceitos em formas abstratas, tais como sinais (letras, números)

Assim, o plano das ideias ocorre no nível do pensamento, onde se formam os juízos e conceitos, e, o plano verbal ocorre no nível no qual os conceitos são verbalmente expressos por signos (termos), com a escolha da terminologia mais adequada. Já no plano notacional ocorre a fixação dos conceitos por meio de formas abstratas de representação (classificação) e significação (sinais, letras e números), sendo este o momento no qual pode ocorrer a combinação de assuntos por meio da síntese. Dahlberg (1979, p. 357) afirma que a "distinção em três níveis auxiliou consideravelmente a tornar mais claro o que pode ser considerado como o objeto da ciência da classificação: é o conceito único e sua capacidade de combinação para representar o conhecimento que o homem tem do mundo".

Assumindo essa perspectiva, Ranganathan considera o assunto (ou conceito, conteúdo do assunto) como uma unidade do pensamento,

[...] um corpo de ideias organizado ou sistematizado, cujas extensão e intensão devem ser coerentes com o domínio de interesse e ajustadas à competência intelectual e ao campo especializado de qualquer indivíduo (RANGANATHAN, 1967, p. 82). 
Dessa forma, o conceito, que representa o conteúdo do assunto, é internalizado no indivíduo dentro de um contexto, porém, possui um caráter individual, pois não inclui as variáveis dos contextos social, político e histórico. Segundo Ranganathan, o "conceito é a formação, depositada na memória, como um resultado de associações de percepções - puras ou compostas - realizadas somente dentro da memória" (ARBOIT; GUIMARÃES, 2013, p. 5). Essa é a fase analítica da abordagem analíticosintética de Ranganathan, utilizada para a identificação dos assuntos que representam o teor dos documentos, e

Isto implica em que a classificação de cada documento exige uma análise de seu título ou um enunciado descritivo de seu conteúdo nos termos dos conceitos que formam os componentes da ciência à qual esse documento pertence. Após a análise e a orientação desses elementos nas chamadas facetas (que são representativas dos tipos de conceitos em áreas especializadas do conhecimento), é possível sintetizá-los em expressões combinatórias que formam a classe, construída analítico-sinteticamente, de um determinado tópico de documento. (DAHLBERG, 1979, p. 357-358).

Com isso, completa-se o ciclo da abordagem analítico-sintética, com a representação dos assuntos dentro das facetas. Ranganathan afirma que "faceta é o termo genérico utilizado para 'assunto básico' e 'isolado'" (1997c, p. 128). Além disso, o autor aponta que, para cada plano de trabalho, a faceta representa uma dimensão diferente, a saber: "Plano das ideias: classe básica e ideia isolada; Plano verbal: assunto básico e termo isolado; Plano notacional: classe básica, isolado e número" (RANGANATHAN, 1997b, p. 85). Sobre a sequência das facetas, o autor explica que

Se duas facetas, A e B, de um assunto, são tais que o conceito por trás de $B$ não poderá ser operatível a menos que o conceito por trás de A seja concedido, até mesmo uma pintura mural não será possível, a não ser que a parede exista para ser pintada, então, a faceta $A$ deve preceder a faceta $B$ (RANGANATHAN, $1997 \mathrm{a}$, p. $25^{3}$ ).

A explanação sobre a sequência das facetas deixa clara a relação que Ranganathan cria entre "assunto" e "conceito", quando o autor afirma que há um conceito por trás das facetas A e B. Essa afirmativa nos leva a

\footnotetext{
3 "If two facets $A$ and $B$ of a subject are such that the concept behind B will not be operative unless the concept behind $A$ is conceded, even as a mural picture is not possible unless the wall exists to draw upon, then the facet A should preceded the facet B".
} 
ponderar que há um conceito por trás de toda faceta. Dessa maneira, neste artigo defendemos e afirmamos a concepção de que o que Ranganathan denomina de "assunto de um documento" é equivalente ao conceito ou aos conceitos contidos nesse documento, uma vez que, inerente ao conteúdo do assunto, está o conceito, que é a representação desse conteúdo.

É preciso lembrar que quando Ranganathan discorre sobre o assunto (conceito), ele está se referindo ao processo inicial da análise facetada, que antecede à classificação de um item documental e, sendo assim, é concebido no plano das ideias. De um modo geral, existem cinco passos para a análise da facetada: (1) coleta de uma amostra representativa dos assuntos; (2) criar uma frase que representa sobre o que é cada assunto; (3) extração de conceitos indexáveis (entidades) desses assuntos; (4) decompor todos os assuntos compostos e/ou complexos em isolados (unidade de pensamento); (5) organizar as entidades em categorias (RANGANATHAN, 1957). Para Ranganathan, no processo de análise do documento ocorre a representação e a organização mental do objeto que será identificado por um termo e, posteriormente, Ihe será atribuída uma notação classificatória.

Ranganathan determinou as formas de análise como "Dissecação, Laminação, Desnudação/ Desfolhamento, Reunião/Agregação e Superposição" (RANGANATHAN, 1967, p. 351) como os procedimentos que devem ser adotados no processo para a formação do assunto e dos isolados. Segundo Campos e Gomes (2003, p. 156), os isolados, "reunidos por um processo de arranjo ou combinação, permitem formar qualquer assunto do documento", e, assim, eles são os conceitos que representam o conteúdo de um documento.

Conforme Ranganathan (1967), as cinco formas de análise podem ser assim descritas: (1) a análise por Dissecação (Dissection) é a divisão de um todo em partes coordenadas (de mesmo nível), denominadas de lâminas, que representam um isolado; (2) a Laminação (Lamination) é a superposição de facetas de um mesmo todo (universo) ou não, que formam camadas de isolados que, quando combinados, compõem um assunto composto; (3) a Desnudação (Desnudation) é a diminuição da extensão e o aumento (ou ampliação ou aprofundamento) da intenção de uma ideia isolada, de forma gradual; (4) a Reunião/Agregação (Loose Assemblage) é a combinação de dois ou mais assuntos básicos (ou compostos) com ideias isoladas, que formam um assunto complexo ou ideia complexa, que expressam relações (de tendência, de comparação, de diferença e influência) entre os componentes de um conjunto, que são denominados de "fases" (fase1; fase2); (5) a Superposição (Superimposition) é a combinação de duas ou mais ideias isoladas pertencentes ao mesmo todo (universo) de ideias isoladas, formando uma ideia isolada superposta ou ideia isolada composta.

No processo de formação dos assuntos (ou conceitos), que é um conjunto de ideias, assim como dos isolados, que é uma ideia isolada (por exemplo, o isolado "criança", que pode fazer parte de diferentes assuntos, tais como "psicologia de criança" e "educação de criança") se estabelecem 
a extensão, mais geral, e a intensão (ou compreensão), mais restrita. A primeira é o conjunto de elementos que constitui uma ideia (classe) e, a segunda, é a característica que confere a um objeto pertencer àquela ideia. Esse é o sentido da abordagem analítico-sintética que possibilita a identificação de conceitos e a sua estruturação e ordenação em classes, de acordo com as categorias existentes em um dado domínio.

Discorrendo sobre as linguagens documentárias, Campos (2001) aponta que uma estrutura sistêmica de conceitos relacionados entre si é criada, por meio da formação de hierarquias (gênero/espécie e todo/parte), de renques (conjuntos compostos a partir de uma única característica de divisão, formando séries horizontais) e de cadeias (séries verticais de conceitos, sendo que cada conceito possui uma característica a mais ou a menos, de acordo com a sua natureza, se ascendente ou descendente, pela Desnudação).

As bases da teoria de Ranganathan comportam a formação de um conjunto de conceitos e a identificação de uma classe que atenda às características desse conjunto de conceitos, com base em um único critério de divisão. No intuito de possibilitar a organização do conjunto de todas as classes identificadas, Ranganathan determinou cinco categorias fundamentais, expressas pelo acrônimo PMEST (Personalidade, Matéria, Energia, Espaço e Tempo), com as quais é possível decompor o conhecimento de qualquer domínio. Para explicar essa forma de analisar um dado domínio, Ranganathan (1967) utilizou a metáfora da "Árvore Baniana" (Banyan tree, uma figueira indiana) que, tal como a Espiral do Conhecimento, é um organismo vivo e dinâmico, pois se alastra e se ramifica por uma extensa área e envia seus galhos aéreos novamente para o solo. Com isso, o pesquisador demonstra que na espiral é possível haver outros tipos de conexões entre conceitos que não apenas de relações hierárquicas, possibilitando representar realidades complexas, que são compostas por diversas dimensões (multidirecional e multidimensional), nas quais ocorrem transformações através do tempo.

Sobre a formação do conceito na teoria de Ranganathan, Kobashi e Francelin (2011, p. 10) apontam que a "lógica subjacente à sua teoria indica que o conceito se estabelece em uma sequência de etapas, recortes, enfim, 'fatias' que determinam o movimento contínuo e infinito de sua Espiral do Universo do Conhecimento", quando são estabelecidas as relações entre os conceitos, a partir de associações por percepções individuais a respeito do mundo real. Nessa perspectiva, Campos e Gomes (2003) acrescentam que

Ranganathan elabora uma série de princípios que visam a permitir que os conceitos de um domínio de saber possam ser estruturados de forma sistêmica, isto é, os conceitos se organizam em renques e cadeias, essas estruturadas em classes abrangentes, que são as facetas, e estas últimas dentro de uma dada categoria fundamental. A reunião de todas as categorias forma um sistema de conceitos de uma 
dada área de assunto e cada conceito no interior da categoria é também a manifestação dessa categoria (CAMPOS; GOMES, 2003, p. 158).

Dessa forma, as etapas para a formação dos conceitos permitem relacionar os assuntos e isolados de forma ilimitada e multidimensional, podendo representar os distintos aspectos do objeto (ou documento ou domínio) analisado. Os pesquisadores da Biblioteconomia e da Ciência da Informação são quase unânimes em considerar a análise facetada como uma metodologia de modelagem de conceitos de uma área do conhecimento. Corroborando com isso, Hjorland (2013) afirma que a análise facetada é a abordagem mais adequada para a organização do conhecimento de um dado domínio. Segundo Dahlberg (1979, p. 364), "podemos dizer que a teoria da classificação, hoje, abrange [1] 0 reconhecimento do conceito como elemento material dos sistemas de classificação; [e 2] a aplicação de uma teoria analítica de conceitos para a representação do conhecimento ou da informação", sendo possível organizar os conceitos de distintas formas. Essa teoria analítica de conceitos foi desenvolvida por Dahlberg e as suas discussões sobre a formação de conceitos estão apresentadas na próxima seção.

\subsection{Formação do "conceito" segundo a teoria de Dahlberg}

A Teoria Analítica do Conceito, desenvolvida por Ingetraut Dahlberg (1972; 1978a; 1978b; 1979; 2006), estabeleceu princípios para a identificação e o entendimento dos conceitos, visando a recuperação da informação por eles representados. A autora criou diretrizes teóricas com o objetivo de ser um "modelo analítico idealizado para elucidar a natureza e a estrutura dos conceitos" (DAHLBERG, 1978b, p. 4). Segundo Dahlberg,

conceito é uma unidade do conhecimento, compreendendo afirmações verdadeiras sobre um dado item de referência, representado numa forma verbal [sendo que:] afirmação verdadeira é a componente de um conceito que expressa um atributo do seu item de referência; item de referência é o componente de um conceito para o qual sua afirmação verdadeira e sua forma verbal estão diretamente relacionadas, sendo assim seu 'referente'; forma verbal (termo/nome) de um conceito é o componente que resume convenientemente ou sintetiza e representa um conceito com o propósito de designar um conceito em comunicação (DAHLBERG, 1978b, p. 147).

Assim, percebe-se que o conceito é composto por uma tríade, sendo que há o referente, que é o objeto a ser conceitualizado, as características desse objeto, que são todos os enunciados verdadeiros (ou predicações) a 
respeito do referente, e, finalmente, a forma verbal (termo) que representa o conceito e é o elemento comunicativo de seu conteúdo, conforme mostra a Figura 1.

Figura 3 - Triângulo do conceito

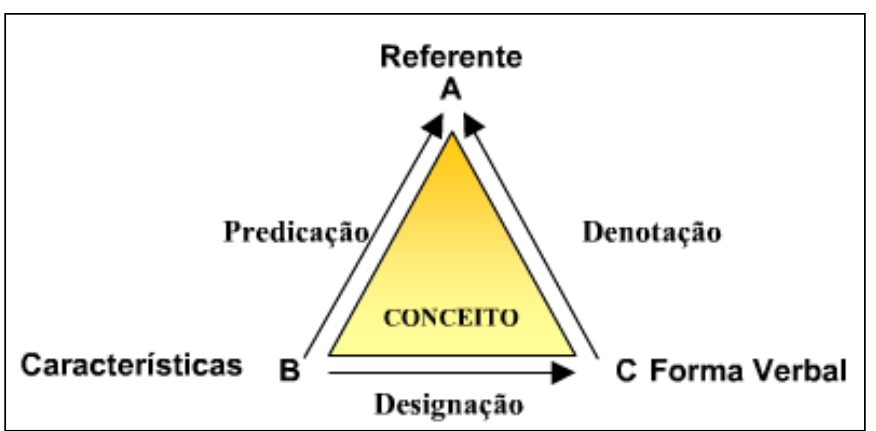

Fonte: DAHLBERG (1978b, p. 149).

Observando o triângulo, é possível notar que ele é um modelo formal para determinar as partes do conceito, pois o conceito fica ao seu centro, sendo formado pela tríade: referente mais características mais forma verbal. É esta última, a forma verbal, que denota o sentido do referente em determinado contexto. Dahlberg (1987 citado por DAHLBERG, 2012) afirma que um conceito expressa a síntese das características necessárias de um referente em dado contexto e propósito, e é designado por um nome (termo) ou mesmo por um código. Dessa forma, um conceito é gerado e motivado "por meio das predicações necessárias sobre um referente, que pode ser um objeto, uma atividade, uma propriedade, uma dimensão ou uma combinação dos mesmos, isto é, pode ser os elementos de qualquer assunto" (idem, p. 143). Sobre as predicações necessárias sobre um referente, a autora aponta que

Tais 'predicações necessárias' formulam as características do conceito, que não devem ser confundidas com as propriedades do conceito, tais como ser um conceito específico e geral ou ser um conceito novo ou de uso corrente. Há conceitos formais e conceitos factuais (Dahlberg, 1980). Conceitos formais advêm das categorias aristotélicas e são usados como facetas, sempre que as classes são subdivididas. Conceitos factuais são combinações de conceitos formais e factuais, que se referem às coisas reais, abstratas ou fictícias. Neste último caso, formas fictícias podem ser, por exemplo, parte das características necessárias de um conceito (DAHLBERG, 2012, p. 143, tradução nossa).

São as características necessárias que delimitam o conceito dentro de um contexto e propósito específicos. Assim, se sobre um referente é necessário estabelecer um conceito factual e descrever uma característica fictícia, isso deverá ser feito. Por exemplo, deve-se diferenciar a escultura, 
que o escultor materializa no mundo real, do objeto real que já existe no mundo, uma vez que ela é o resultado do imaginário do artista, que não edifica o objeto, mas o transforma a partir de sua perspectiva pessoal, podendo remover ou adicionar elementos.

Para Dahlberg (1978a), as características de um conceito podem ser dos seguintes tipos: 1) essenciais: encontradas em todos os referentes relacionados a um conceito; (2) acidentais: identificados em alguns dos referentes relacionados a um conceito, mas não sendo inerente a ele; e (3) individualizantes: encontradas em um único referente. Segundo a autora, as características podem ser hierarquicamente organizadas, das mais gerais às mais específicas, sendo que a característica mais geral (que possui maior amplitude de extensão) pode ser considerada uma classe básica.

A teoria de Dahlberg tem por base os princípios analíticos de Aristóteles e os princípios analítico-sintéticos da teoria de Ranganathan (DAHLBERG, 1978b). Dos aportes de Aristóteles, a teoria desenvolvida por Dahlberg destaca que, na abstração do conceito, para a apreensão daquilo que é inteligível e passível de representação, ocorre a fatoração do objeto em suas partes constituintes e elementos individuais, a partir da determinação de uma hierarquia das proposições verdadeiras sobre o conceito, que culminam em uma categoria genérica. Nesse sentido, a formação do conceito é retirada da experiência, a posteriori, uma vez que para Aristóteles a realidade é estruturada em grupos hierárquicos. Esse filósofo trouxe uma grande contribuição ao ser o primeiro a determinar a existência da divisão taxonômica em classes de gênero/espécie, classe essa que mais tarde foi reformulada e explicitada por Porfírio. Essa estrutura é até hoje observada na organização de conceitos em tesauros, quando divide uma classe geral (gênero) em espécies, a partir da aplicação de uma característica comum. Segundo Aristóteles, a existência de gêneros e espécies é dependente da existência de um princípio classificatório único ou "característica de uma classificação", que é o "elemento que serve para reunir os grupos segundo as semelhanças que apresentam" (BARBOSA, 1969, p. 14) e, assim, individualizando-os. Segundo Dahlberg (1978a), chega-se a objetos individuais

[...] toda vez que o objeto é pensado como único, distinto dos demais, constituindo uma unidade inconfundível (coisas, fenômenos, processos, acontecimentos, atributos, etc.) pode-se falar de objetos individuais. Pode-se dizer que o que caracteriza os objetos individuais é a presença das formas do tempo e espaço. Os objetos individuais estão aqui e agora. Ex.: esta casa, esta mesa, este automóvel, esta partida de futebol, etc. (DAHLBERG, 1978a, p. 101).

Nessa forma de pensar a realidade e a classificação de seus objetos, é possível observar a forte natureza analítica e lógico-positivista na teoria 
de Dahlberg, ideias que são atribuídas aos princípios analíticos de Aristóteles.

Dessa forma, Dahlberg utiliza, na elaboração de sua teoria, os princípios dos quatro predicáveis estipulados por Aristóteles, que são: (1) Definição: que revela a essência daquilo que se predica, pois o gênero mais a diferença específica formam a definição; por exemplo, não se define um homem afirmando que ele está adoentado (acidente), mas pronunciando que ele é animal racional; por isso, a espécie não é mencionada explicitamente nos predicáveis de Aristóteles, aparecendo somente mais tarde, na formulação dos seus predicáveis, realizada por Porfírio, quando ela se dá pela forma de predicação de um sujeito a partir da diferença específica; nesse caso do exemplo teríamos: animal (gênero) e racional (diferença) = homem (espécie); (2) Propriedade: que descreve as características próprias daquilo que é categorizado; por exemplo, é uma propriedade do homem aprender gramática e, se é capaz de aprender gramática, é um homem (inferência lógica); (3) Gênero: que associa elementos que mantêm uma relação de semelhança entre si, desde que essa relação tenha por base algo que é inerente aos elementos; por exemplo, do homem e do boi seria apropriado dizer que são animais, e, portanto, que são do mesmo gênero; e (4) Acidente: que identifica características transitórias, situacionais, que podem pertencer a algo em um dado momento, mas que pode deixar de pertencer sem que haja a perda de essência; por exemplo, a atribuição da posição sentada não é inerente a "José", pois, se "José" se levantar ou deitar, a sua definição, propriedade e gênero se manterão inalteráveis.

As dez categorias para a determinação formal do ser (objeto), formuladas por Aristóteles, também contribuíram na criação da teoria de Dahlberg: substância, quantidade, qualidade, relação, lugar, tempo, posição, estado, ação e sofrimento da ação. Ainda que Ranganathan não tenha exposto isso, o desenvolvimento de sua teoria também levou em consideração tais categorias.

Sobre os princípios analítico-sintéticos da teoria de Ranganathan que deram sustentação à teoria analítica do conceito, Dahlberg considerou que "todo enunciado sobre objetos contém um elemento do respectivo conceito. Estes elementos identificam-se com as chamadas características dos conceitos" (DAHLBERG, 1978a, p. 102). Essa decomposição do conceito, dentro do método analítico-sintético, é a fase analítica, da análise do conceito. A autora afirma que "um enunciado pode tornar-se sujeito de novo enunciado e assim sucessivamente até atingirmos uma característica tão geral que possa ser considerada uma categoria. (Entende-se aqui por categoria o conceito na sua mais ampla extensão)" (DAHLBERG, 1978a, p. 102). Já a fase sintética, a autora explica que "se o conceito ainda não tem nome é possível formulá-lo pela síntese das características descobertas. Tem-se exemplo disto nos novos elementos descobertos pela química" (DAHLBERG, 1978a, p. 103). Dahlberg (1978b) determina que há conceitos de naturezas diferentes, a saber: (1) gerais: que se referem a um conjunto de itens de determinado tipo, como, por exemplo, todos os alunos do gênero masculino na sala de aula; (2) 
especiais: que apontam apenas itens de determinado tipo, como, por exemplo, alunos do gênero masculino na sala de aula que usam camisa branca; e (3) individuais: que identificam somente um único item, como, por exemplo, um determinado aluno do gênero masculino na sala de aula.

Em 1992, Dahlberg apontou a Teoria Analítica do Conceito, que é orientada ao referente, como parte integrante da disciplina Organização do Conhecimento, uma vez ela "o que permite compreender um conceito como portador de elementos/características adquiridos a partir de predicações sobre o referente" (DAHLBERG, 1992, p. 66, tradução nossa). A autora aponta que, nesse processo, a análise pode contar com os subsídios de sete campos filosóficos: Lógica, Teoria da Ciência, Epistemologia, Ontologia, Fenomenologia, Aletiologia (doutrina da verdade) e Metafísica.

Hjorland (2007) reconhece que a Teoria Analítica do Conceito incluiu visões filosóficas mais amplas, e afirma que ela compreende

[...] um grande campo nas ciências cognitivas, filosofia da mente, linguística, sociologia e também áreas aplicadas tais como ciência da computação (com Inteligência Artificial), terminologia e tradução. Dentro da organização do conhecimento, a Teoria do Conceito não pode ignorar tais contribuições interdisciplinares para suas bases (HJORLAND, 2007, p. 1, tradução nossa).

O autor sugere que são necessárias novas reflexões acerca dessa teoria, pois ele acredita que uma teoria para o conceito deve integrar diversas concepções teóricas e filosóficas para que seja consistente. Corroborando com isso, Kobashi e Francelin (2011, p. 15) apontam que "a força das teorias é medida pela sua evolução no tempo histórico e grau de influência nos campos de conhecimento". Para os autores, na disciplina Organização do Conhecimento é preciso que ocorram debates tais como os que acontecem no campo da Terminologia e das Linguagens Documentárias, que "introduziram discussões sobre os limites dos cânones normativos" (KOBASHI; FRANCELIN, 2011, p. 15), contestando os princípios racionalistas. Dessa forma, pode-se pensar no convívio de diferentes concepções sobre o conceito de "conceito" no campo da Biblioteconomia e da Ciência da Informação, dependendo do fundamento teórico adotado pelo pesquisador, seja do empirismo, racionalismo, historicismo ou pragmatismo (HJORLAND, 2007).

Foi a partir dessas reflexões que se tentou chegar a um conceito de "conceito" empregando os princípios da teoria de Cabré, a TCT e as concepções pragmáticas de conceito, nas quais o enunciado de um conceito é tratado em virtude da função que tal enunciado desempenha em dado contexto de uso. 


\section{Em busca de uma reformulação do conceito de "conceito"}

Na perspectiva da concepção pragmática, Hjorland (2008a) afirma que devem-se levar em consideração as questões sobre

Que tipo de trabalho o conceito tem que fazer por nós, e de que maneira as diferentes formas de compreender este conceito podem facilitar ou contrariar o que nós queremos realizar. Quando estamos trabalhando com ferramentas terminológicas e semânticas, tais como dicionários, sistemas de classificação e tesauros, o conceito de conceito parece inevitável e os progressos na compreensão de conceitos podem influenciar a própria maneira de trabalho na Terminologia, na Biblioteconomia e Ciência da Informação e em muitas áreas afins (HJORLAND, 2008a, on-line).

Assim, ao desenvolver instrumentos terminológicos e semânticos é preciso determinar alguns elementos, tais como o propósito desejado, as características do domínio modelado e as necessidades de informação dos potenciais usuários.

Foi a partir desses elementos e tendo por base a TCT, a concepção pragmática e as teorias do conceito que consideram o conceito em razão de sua função no contexto de uso que Maculan (2015) propôs um conceito para "conceito":

Conceito é composto pela tríade referente+significado+significante. Sua formação se inicia como uma concepção intelectual e mental sobre um referente, que é um objeto (entidade concreta ou abstrata) em dado domínio de uso. As propriedades, características e atributos desse referente, assim como os seus relacionamentos com outros referentes, estão externalizados e traduzidos em seu significado. Esse significado é revelado por meio de uma definição, elaborada com a função de delimitar e cristalizar o ato intencional do significado do referente. Essa definição registra tudo aquilo que é conhecido sobre o referente e que é mandatório para atender a um propósito determinado, dentro de um contexto específico de uso. 0 conceito, assim constituído, será representado por um significante, que é uma expressão verbal ou simbólica, que será utilizado como elemento comunicativo de mediação, sem que, necessariamente, haja um vínculo indissociável entre significante e referente (MACULAN, 2015, p. 105).

Nessa definição, a autora denomina de "significado" e "significante" aquilo que Dahlberg (1978a) designa, respectivamente, de "características" e "forma verbal". A proposta de Maculan (2015) articula o triângulo de Dahlberg (Figura 1) com a ideia do triângulo de Ogden e Richards (Figura 2), conforme mostra a Figura 4.

Figura 4 - Proposta Maculan (2015) para o conceito de "conceito" 


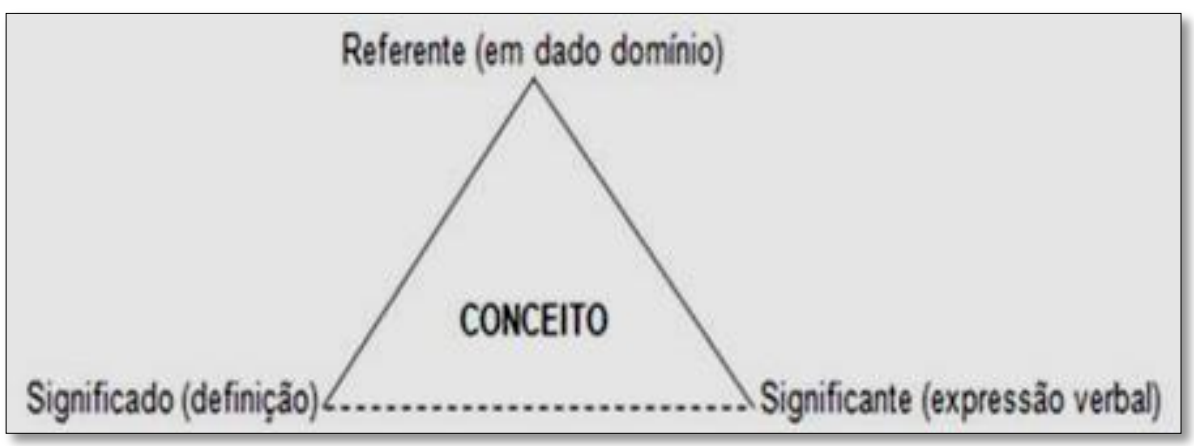

Fonte: MACULAN (2015, p. 106).

Observa-se, pela Figura 4, que o conceito ocupa o centro da tríade, tal como ocorre na proposta de Dahlberg (1978a), assim como o referente é um objeto em dado domínio, cujo significado tem relação direta com o seu contexto de uso.

O contexto de uso é discutido por Wittgenstein (1996) quando afirma que "o significado de uma palavra somente pode ser alcançado se, antes, é determinado o contexto de seu uso" (MACULAN, 2015, p. 66), sendo este significado dependente do acordado entre os pares de uma comunidade discursiva, num contexto pragmático de comunicação (SOUZA; HINTZE, 2010), pois

[...] a importância do uso ganha uma dimensão mais complexa em Wittgenstein porque não se refere apenas à inserção de palavras em frases, mas a uma situação de ação com finalidade prática, como um exercício de influência de uns sobre os outros em um ambiente complexo. A esse ambiente, o autor denominou "jogo de linguagem" ou Sprachspiel, uma atividade regulada e partilhada (SOUZA; HINTZE, 2010, p. 115).

Dessa forma, o "jogo" refere-se ao consenso sobre os conceitos compartilhados dentro de um domínio, "cujos significados são construídos pela interação de seus atores sociais, visando a alcançar determinados efeitos ou objetivos práticos" (MACULAN, 2015, p. 66), sugerindo que a pragmática está anterior à semântica. Sobre isso, Bakhtin (2006) determina que

Todo signo, como sabemos, resulta de um consenso entre indivíduos socialmente organizados no decorrer de um processo de interação. Razão pela qual as formas do signo são condicionadas tanto pela organização social de tais indivíduos como pelas condições em que a interação acontece. Uma modificação destas formas ocasiona uma modificação do signo. É justamente uma das tarefas da ciência das ideologias estudar esta evolução social do signo linguístico (BAKHTIN, 2006, p. 43, grifos do autor citado).

Sendo assim, o domínio (mais especificamente tratado no campo da Teoria do Conceito) e o discurso (especialmente tratado no campo da Teoria Comunicativa da Terminologia) se completam, uma vez que são os lugares onde o processo interacional acontece, tornando-se insumo na 
construção de instrumentos terminológicos. É nessa perspectiva que Maculan (2015) propõe designar de "significado" o que Dahlberg denomina de "características". O "significado" é a definição do conceito que torna material (concretiza) o sentido acordado entre os atores em um dado domínio, explicitando "as relações que ele mantém com outros referentes, naquele contexto de uso e de acordo com uma finalidade e propósitos específicos de construção do instrumento terminológico" (MACULAN, 2015, p. 83). Dessa forma, na definição são predicados os elementos imprescindíveis para atender ao objetivo escolhido para a modelagem.

De forma semelhante ao triângulo de Ogden e Richards (Figura 2), a proposta de Maculan (2015) aponta o "significante" para o que Dahlberg (Figura 3) denomina de "forma verbal", que é o signo comunicativo do conceito. E a autora, diferente da determinação de uma relação direta e indissociável entre referente e forma verbal (significante), apontada no triângulo de Dahlberg (Figura 3), propõe adotar a linha pontilhada na base do triângulo, de acordo com Ogden e Richards (Figura 2). Com isso, Maculan (2015) sugere acatar os princípios da TCT, de Cabré, pois a linha pontilhada entre referente e significante leva em consideração que mesmo em domínios de especialidade a linguagem possui ambiguidade (imprecisão do sentido utilizado), sobretudo a polissemia (ambiguidade lexical, com um mesmo signo expressando significados diferentes dentro de um mesmo campo semântico ${ }^{4}$ ), tal como ocorre na língua geral.

Como exemplo para a polissemia (ambiguidade lexical) intra e inter domínios, Maculan (2015, p. 107, grifos nossos) apresentou o caso das definições dos conceitos para o signo "mistura" no domínio da Agricultura (que apresenta duas definições) e no domínio da Química (com uma definição):

Expressão verbal: Mistura

Contexto: a) Agricultura; Definição 1a: composto de resíduos de dejeto animal usado como adubo e formado a partir da técnica de compostagem. Sinônimo: composição; composto. Definição 2a: cruzamento de raças diferentes de animais, gerando a miscigenação. Sinônimo: cruzamento; hibridação.

Contexto: b) Química; Definição 1b: composto de diferentes elementos químicos para formar uma nova combinação. Sinônimo: solução complexa; composição; fusão.

É possível perceber que entre domínios distintos (inter domínios), ou seja, entre os domínios da Agricultura e da Química, o mesmo signo "mistura" representa conceitos diferentes, o que pode ser observado a partir das três definições apresentadas. Ou seja, há polissemia inter domínios. Nessa situação de polissemia (conforme definições apresentadas em 1a, 2a e 1b) inter domínios, o próprio contexto (campo

\footnotetext{
4 Especifica o lugar que o signo ocupa na estrutura semântica do instrumento terminológico, ajudando a controlar os homônimos.
} 
conceitual ou nocional) de uso pode fazer a identificação do conceito (registrado na definição) que está sendo utilizado. Assim, determina-se qual o sentido empregado a partir da relação que o conceito "mistura" estabelece com outros conceitos na estrutura do instrumento, principalmente porque, em geral, os instrumentos terminológicos, tal como o tesauro, são desenvolvidos para um domínio específico.

Por outro lado, a polissemia intra domínio, que ocorre em um mesmo domínio, pode ser observado a partir das duas definições (conforme apresentadas em 1a e 2a) que são estabelecidas para o signo "mistura" que, dentro do mesmo domínio, da Agricultura, está ligado a dois conceitos diferentes. Nesse caso, a determinação de qual sentido está sendo empregado é realizado a partir da identificação do campo semântico, ou seja, é quando estabelecemos todas as significações que um signo possui, analisando esse signo do ponto de vista de sua polissemia.

A representação dessas duas polissemias, a inter e intra domínios, estão apresentadas na Figura 5.

Figura 5 - Representação de polissemia intra e inter domínios

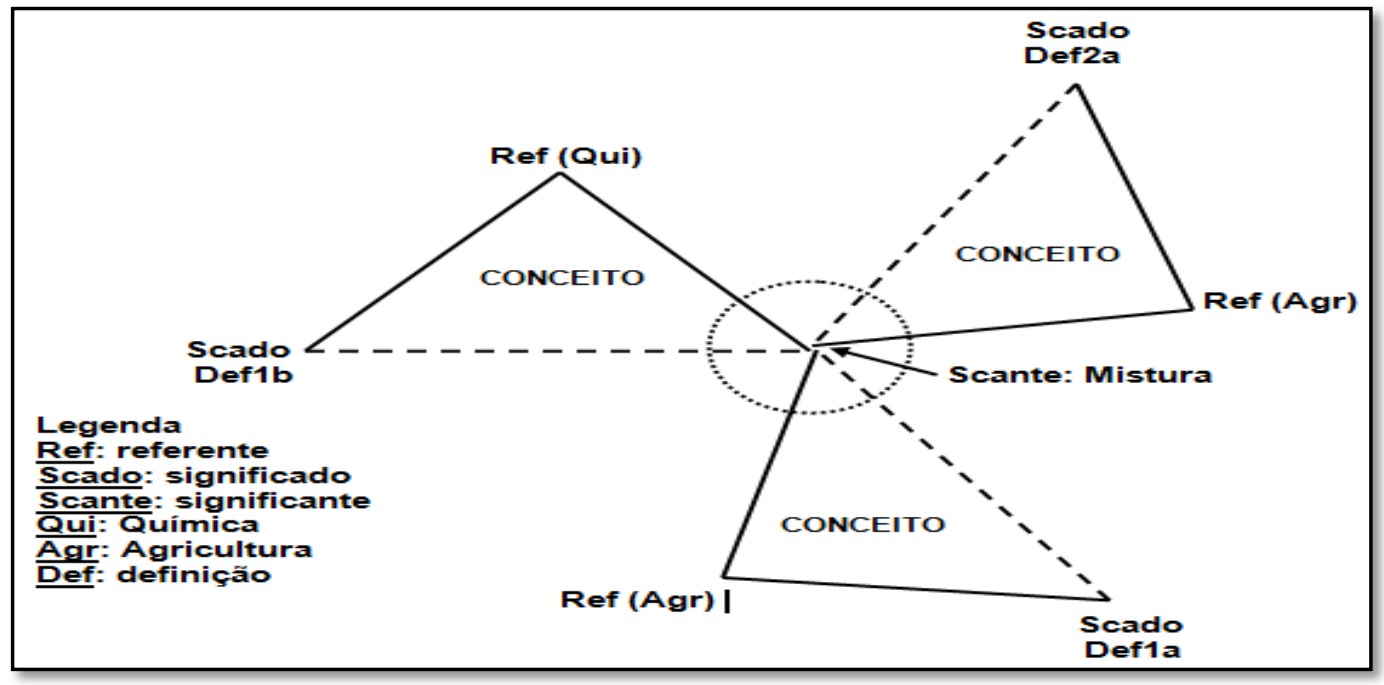

Fonte: MACULAN (2015, p. 108).

Percebe-se pela Figura 5 que a representação do significante "mistura" o conecta a três distintos conceitos, a saber: existem dois conceitos (significados) diferentes ligados ao significante "mistura" no domínio da Agricultura (conforme definições Def1a e Def2a), o que representa a polissemia intra domínio, e há um conceito (significado) ligado ao significante "mistura" no domínio da Química (conforme definição Def1b), o que representa a polissemia inter domínios.

A representação da Figura 5 demonstra os princípios da TCT, de Cabré, que tem uma abordagem de análise descritiva, no qual considera que os dados terminológicos não são unívocos e nem universais (CABRÉ, 1999). Essa ideia é contrária ao que preconiza Wüster. Nota-se, na Figura 5, que o significante "mistura" caracteriza-se como um termo polissêmico 
(inter e intra domínios), pois é utilizado para representar os três conceitos em questão.

Para o caso registrado na Figura 5, alcança-se o controle da polissemia por meio das definições dos conceitos (campo semântico), e também pelo lugar que cada significante ocupa nas estruturas hierárquicas (campo conceitual), tanto do domínio da Agricultura quanto do domínio da Química. Como afirma Krieger (2001), o termo (significante) escolhido como elemento de comunicação possui uma vertente conceitual, que expressa a construção de um conhecimento sobre um dado domínio, e outra vertente linguística, que expressa os aspectos sociais e históricos da transferência de tal conhecimento entre os pares. Dessa maneira, uma unidade terminológica carrega os elementos contextuais e também os discursivos, abarcando as representações dos campos conceituais e dos campos semânticos.

Outro fenômeno que também ocorre tanto na linguagem de especialidade (ou de um domínio) quanto na linguagem natural é da sinonímia (ou equivalência). Utilizando a definição do termo "mistura" no campo da Química, há três termos em sinonímia: Def1b: solução complexa; composição; fusão. Propõe-se representar esse fenômeno conforme Figura 6.

Figura 6 - Representação de sinonímia

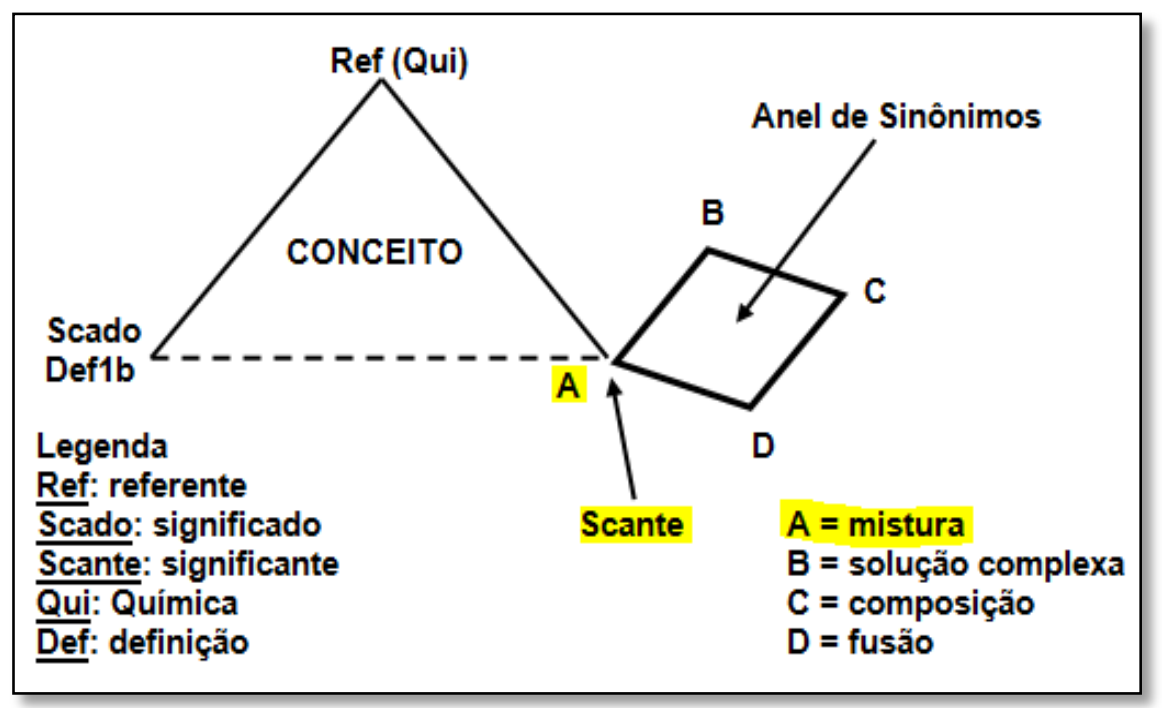

Fonte: MACULAN (2015, p. 109).

Na representação do fenômeno da sinonímia no domínio da Química (conforme Def1b), demonstrada através do instrumento Anel de Sinônimos ${ }^{5}$ na Figura 6, nota-se que o termo "mistura" (A) está em relação de equivalência com os termos $B, C$ e $D$. Principalmente em sistemas digitais de recuperação de informações, o Anel de Sinônimos garante que um conceito que possa ser representado por dois ou mais

\footnotetext{
${ }^{5}$ É um tipo de sistema de organização do conhecimento (SOC) utilizado para representar termos em equivalência semântica em um dado domínio.
} 
significantes (forma verbal; unidade lexical), que estão em relação de equivalência (ou sinonímia), será recuperado pelo usuário com qualquer um dos termos utilizados em uma busca.

Além da representação do fenômeno da sinonímia, a Figura 6 sintetiza, graficamente, a proposta de Maculan (2015, p. 109) para o conceito de "conceito", "apresentando-o como composto pela tríade 'referente+significado+significante', assim como designando os sinônimos do significante através do Anel de Sinônimos, sempre que necessário", que tem por base os princípios da Teoria do Conceito e da TCT.

\section{Considerações Finais}

Neste artigo o conceito de "conceito" foi descrito e analisado nas áreas da Linguística, Terminologia, Biblioteconomia e Ciência da Informação, buscando insumos para o campo da construção de tesauros conceituais.

Da Linguística, trouxe, principalmente, a visão de conceito em Saussure, que estabelece uma inerente ligação entre o significante (forma) e o seu significado (substância), sendo o signo constituído pelo grupo social (contexto de uso), de forma arbitrária. Contudo, ficou claro que há críticas à visão de Saussure.

Do campo da Terminologia, foram apresentadas diferentes concepções para o conceito de "conceito", desde a origem da área, denominada de terminologia clássica. Reconhecendo a validade dos princípios advindos da Teoria Geral da Terminologia (TGT), de Wüster, que influenciaram os avanços nos fundamentos para o desenvolvimento de tesauros, as limitações desses princípios normalizadores para contextos comunicativos exigiram a busca por outras formas de representação. Nessa perspectiva, a Teoria Comunicativa da Terminologia (TCT) considera o termo como uma unidade linguístico-pragmática, que faz parte do processo comunicativo humano e, como tal, tem como particularidade transmitir conteúdos de diversos domínios, mas é conduzida pelas mesmas regras e caracterizada pelos mesmos fenômenos de polissemia, sinonímia e variação linguística, presentes na linguagem geral. Sendo assim, a univocidade é, em parte, contestada.

Da Biblioteconomia e Ciência da Informação, foram discutidos os sentidos para o conceito na Teoria da Classificação Facetada, de Ranganathan, e na Teoria Analítica do Conceito, de Dahlberg. Com uma abordagem que leva em consideração a função do conceito em um contexto de uso, o aspecto analítico-sintético da teoria de Ranganathan é convergente com a proposta da TGT, no sentido em que considera que as unidades conceituais são interligadas e interdependentes. Assim como o fez Wüster, na TGT, a univocidade do significado de um termo é observada na Teoria do Conceito de Dahlberg, que possui uma forte natureza analítica e lógico-positivista. No final dos anos 1970, Dahlberg modelava conceitos técnico-científicos, considerados os únicos plenamente descritíveis ou definíveis (DAHLBERG, 1978a). Ressalta-se que, à época do desenvolvimento da sua teoria, apenas iniciava-se a possibilidade do 
tratamento de dados usando a informática e, talvez, as tecnologias disponíveis ainda exigissem dos sistemas de recuperação de informação essa natureza positivista e prescritiva.

Como objetos para pesquisas futuras, apresentamos uma relação do campo da semântica, apresentada por Lopes (2005, p. 234): "a) a linha semântica de Saussure e Hjelmslev; b) a linha semântica lógica (ou da 'palavra' isolada); c) a linha da semântica contextual; d) a linha da semântica contexto-situacional; e) a linha da semântica transformacional". Consideramos que são campos de estudos que podem trazer insumos importantes para o campo da construção de tesauros.

Finalmente, como contribuição mais significativa, este artigo apresentou uma proposta para se refletir sobre o conceito de "conceito" no âmbito da construção de tesauros, que foi elaborada por Maculan (2015), e que foi amparada nas bases da Teoria do Conceito (DAHLBERG, 1978a; 1978b) e está em adequação aos princípios Teoria Comunicativa da Terminologia (TCT) (CABRÉ, 1995; 1999). Espera-se que o conteúdo deste estudo traga discussões construtivas no sentido de fazer avançar nosso entendimento sobre a representação e entendimento do conceito de "conceito" no campo da organização e representação do conhecimento e da informação, que possa ser generalizada para diferentes contextos de uso e comunicação.

\section{Referências}

ABBAGNANO, N. Dicionário de Filosofia. São Paulo: Martins Fontes, 1998.

ARBOIT, A. E.; GUIMARÃES, J. A. C. Conhecimento e linguagem na organização do conhecimento: aspectos dialógicos a partir da concepção de Bakhtin. In: ENCONTRO NACIONAL DE PESQUISA EM CIÊNCIA DA INFORMAÇÃO, 14., de 29 de outubro a 1 de novembro, Florianópolis, 2013. Anais... Florianópolis, SC: ENANCIB, 2013.

BAKHTIN, M. Marxismo e filosofia da linguagem. 12. ed. São Paulo: Hucitec, 2006.

BARBOSA, A. Teoria e prática dos sistemas de classificação bibliográfica. Rio de Janeiro: Instituto Brasileiro de Bibliografia e Documentação, 1969.

BARROS, L. A. Curso básico de Terminologia. São. Paulo: USP, 2004. $296 p$.

BARROS, L. A. Aspectos epistemológicos e perspectivas científicas da terminologia. Ciência e Cultura, São Paulo, v. 58, n. 2, abr./jun. 2006. Disponível em: <http://cienciaecultura.bvs.br/scielo.php?pid=S000967252006000200011\&script=sci_arttext>. Acesso em: 22 ago. 2016.

BENVENISTE, É. Problemas de Linguística Geral. Campinas: Pontes, 1989. v. 2.

BLIKSTEIN, I. Kaspar Hauser ou a fabricação da realidade. São Paulo: Cultrix; EDUSP, 1983. 
BORBA, F. S. Uma gramática de valências para o português. São Paulo: Ática, 1996.

BORNEMANN, N. B. O. Ferdinand de Saussure e o objeto da Linguística. Linguasagem, São Paulo, v. 18, p. 1-11, 2011.

BOUTIN-QUESNEL, R. et al. Vocabulaire systématique de la terminologie. Cahiers de l'Office de la langue française. Québec: Publications du Québec, 1985 citado por BARROS, L. A. Curso básico de Terminologia. São. Paulo: EdUSP, 2004. 296p.

CABRÉ, M. T. La Terminologia: teoría, metodología, aplicaciones. Barcelona: Antartida/Empuries, 1993. 529p.

CABRÉ, M. T. La terminología hoy: concepciones, tendências y aplicaciones. Ci. Inf., Brasília, v. 24, n. 3, 1995.

CABRÉ, M. T. La terminología: representación y comunicación. Barcelona: Institut Universitari de Linguística Aplicada, Universitat Pompeu Fabra, 1999. 369p.

CAMPOS, M. L. A. Linguagem documentária: teorias que fundamentam sua elaboração. Rio de Janeiro: EUFF, 2001.

CAMPOS, M. L. A.; GOMES, H. E. Organização de domínios de conhecimento e os princípios ranganathianos. Perspect. Ci. Inf., Belo Horizonte, v. 8, n. 2, jul./dez. 2003.

CAMPOS, M. L. A.; GOMES, H. E. Metodologia de elaboração de tesauro conceitual: a categorização como princípio norteador. Perspect. Ci. Inf., Belo Horizonte, v. 11, n. 3, p. 348-359, dez. 2006. Disponível em: <http://www.scielo.br/scielo.php?script=sci_arttext\&pid=S1413-

99362006000300005\&lng=en\&nrm=iso>. Acesso em: 5 set. 2016.

CARVALHO, C. Para compreender Saussure. 12. ed. Petrópolis: Vozes, 2003.

DAHLBERG, I. Teoria da classificação, ontem e hoje. Tradução de Henry B. Cox. Palestra apresentada à Conferência Brasileira de Classificação Bibliográfica, Rio de Janeiro, 12-17 de setembro de 1972. Anais... Brasília, IBICT/ABDF, 1979. v. 1, p. 352-370.

DAHLBERG, I. Teoria do conceito. Tradução Astério Tavares Campos. Ci. Inf., Rio de Janeiro, v. 7, n. 2, p. 101-107, 1978a.

DAHLBERG, I. A referent-oriented, analytical concept theory of Interconcept. International Classification, v. 5, n. 3, p. 122-151, 1978b.

DAHLBERG, I. Wissensmuster und Musterwissen im Erfassen klassifikatorischer Ganzheiten. In: DAHLBERG, I.; WOLFGANG, D. (Ed.). Wissensstrukturen und Ordnungsmuster: 4. Fachtagung der Gesellschaft für Klassifikation, Salzburg 16-19, April 1980. Proceedings... Frankfurt: INDEKS Verlag, 1980. p. 294-315.

DAHLBERG, I. Die gegenstandsbezogene analytische Begriffstheorie und ihre Definitionsarten. In: GANTER, B.; WILLE, R.; WOLFF, K. E. (Ed). 
Beiträge zur Begriffsanalyse: Vorträge der Arbeitstagung Begriffsanalyse, Darmstadt: B. I. Wissenschaftsverlag, 1987. p. 9-22.

DAHLBERG, I. Knowledge organization and Terminology: phisolophical and linguistic bases. International Classification, Frankfurt, v. 19, n. 2, p. 6571, 1992.

DAHLBERG, I. Knowledge organization: a new science? Knowledge Organization, Frankfurt, v. 33, n. 1, p. 11-19, 2006.

DAHLBERG, I. A systematic new lexicon of all knowledge fields based on the information coding classification. Knowledge Organization, v. 39, n. 2, 2012.

DUBOIS, J. et al. Dicionário de linguística. São Paulo, Cultrix, 1997.

FAULSTICH, E. A socioterminologia na comunicação científica e técnica. Ciência e Cultura, v. 58, n. 2, p. 27-31, abr./jun. 2006.

FERRATER-MORA, J. Dicionário de filosofia. 2. ed. São Paulo: Loyola, 2004. t.1-4.

FINATTO, M. J. B. Definição terminológica: fundamentos teóricometodológicos para sua descrição e explicação. 2001. 395f. Tese (Doutorado em Estudos da Linguagem) - Instituto de Letras, Universidade Federal do Rio Grande do Sul, Porto Alegre, 2001.

FIORIN, J. L. (Org.) et al. Introdução à Linguística. São Paulo: Contexto, 2003. v. 1 e 2.

FUGMANN, R. Subject analysis and indexing: theoretical foundation and practical advice. Frankfurt-am-Main: INDEKS Verlag, 1993.

GAUDIN, F. Pour une socioterminologie. Rouen: PublicationsUniversité de Rouen, 1993.

HJORLAND, B. Semantics and knowledge organization. Annual Review of Information Science and Technology, v. 41, p. 367-405, 2007.

HJORLAND, B. Concept in knowledge organization (KO). The epistemological lifeboat, 2008.2 Disponível em: <http://www.iva.dk/bh/lifeboat_ko/CONCEPTS/concept_in_knowledge_or ganizatio.htm>. Acesso em: 12 set. 2016.

HJORLAND, B. Concept theory. Journal of the American Society for Information Science and Technology, v. 60, n. 8, p. 1519-1536, 2009.

HJORLAND, B. Facet analysis: the logical approach to knowledge organization. Information Processing \& Management, v. 49, n. 2, p. 545$557,2013$.

JUCHEM, A. Saussure, Benveniste e o objeto da linguística. Cadernos do $I L$, Porto Alegre, n. 36, jun. 2008. Disponível em: http://www.seer.ufrgs.br/cadernosdoil/>. Acesso em: 18 ago. 2016. 
KOBASHI, N. Y.; FRANCELIN, M. M. Conceitos, categorias e organização do conhecimento. Informação e Informação, Londrina, v. 16, n. 3, p. 124, jan./jun. 2011.

KRIEGER, M. G.; FINATTO, M. J. B. Introdução à Terminologia: teoria e prática. São Paulo: Contexto, 2004. 223p.

LA BARRE, K. Facets, search and discovery in next generation catalogs: Informing the future by revisiting past understanding. In: INTERNATIONAL CONFERENCE OF THE ISKO, 11., 2010. Proceedings... [s.l.: s.n.], 2010. p. 269-275.

LOPES, E. Semântica. In: FUNDAMENTOS da lingüística contemporânea. 21. ed. São Paulo: Cultrix, 2005. p. 232-335.

MACULAN, B. C. M. S. Estudo e aplicação de metodologia para reengenharia de tesauro: remodelagem do THESAGRO. 2015. 345f. Tese (Doutorado em Ciência da Informação) - Universidade Federal de Minas Gerais, Escola de Ciência da Informação. Belo Horizonte: UFMG, 2015.

MAIMONE, G. D.; TÁLAMO, M. F. G. M. Linguística e terminologia: contribuições para a elaboração de tesauros em ciência da informação. DataGramaZero - Revista de Ciência da Informação, v. 12, n. 2, abr. 2011. Disponível em: <http://www.dgz.org.br/abr11/F_I_art.htm>. Acesso em: 6 set. 2016.

NASCIMENTO, E. M. F. S. Saussure: o estruturalista antes do termo. Diálogos Pertinentes - Revista Científica de Letras, Franca/SP, v. 4, n. 4, p. 259-276, jan./dez. 2008.

RANGANATHAN, S. R. Prolegomena to library classification. London: Asia Publishing House, 1957.

RANGANTHAN, S. R. Prolegomena to library classification. Bombay: Asia Publishing House, 1967.

RANGANATHAN, S. R. Hidden roots of classification. In: NEELAMEGHAN, A. (Org.). S. R. Ranganathan's postulates and normative principles: applications in specialized databases design, indexing and retrieval. Bangalore: Sara Ranganathan Endowment for Library Science, 1997a. Chapter 1, p. 1-42.

RANGANATHAN, S. R. Design of depth classification: metodology. In: NEELAMEGHAN, A. (Org.). S. R. Ranganathan's postulates and normative principles: applications in specialized databases design, indexing and retrieval. Bangalore: Sara Ranganathan Endowment for Library Science, 1997b. Chapter 3, p. 75-126.

RANGANATHAN, S. R. Subject heading and facet analysis. In: NEELAMEGHAN, A. (Org.). S. R. Ranganathan's postulates and normative principles: applications in specialized databases design, indexing and retrieval. Bangalore: Sara Ranganathan Endowment for Library Science, 1997c. Chapter 4, p. 127-146. 
SAGER, J. C. A practical course in terminology processing. Amsterdam/Philadelphia: John Benjamins, 1990.

SANTOS, I.; NASCIMENTO, M. E. F. Bakhtin e Wittgenstein: teorias em diálogo. Theoria - Revista Eletrônica de Filosofia, Pouso Alegre, n. 3, p. 76-85, 2010.

SILVEIRA, M. R. A. Produção de sentidos e construção de conceitos na relação ensino/aprendizagem da matemática. 2005. 176f. Tese (Doutorado em Educação) - Faculdade de Educação, Universidade Federal do Rio Grande do Sul, Porto Alegre, 2005.

SOUZA, R. A.; HINTZE, A. C. J. Pragmatismo e linguística: interfaces e intersecções. Cognitio-Estudos: Revista Eletrônica de Filosofia, São Paulo, v. 7, n. 2, p. 108-120, jul./dez. 2010.

SVENONIUS, E. The intellectual foundations of information organization. Cambridge: The MIT Press, 2000.

WITTGENSTEIN, L. Investigações filosóficas. Tradução de M. G. Montagnoli. Petrópolis: Vozes, 1996. 